\title{
Mathematics for language, language for mathematics
}

\author{
Lenka Tejkalova Prochazkova ${ }^{1}$ \\ ${ }^{1}$ Department of Mathematics and Didactics of Mathematics, Charles University, Prague, Czech Republic \\ For correspondence: lenka.tejkalova@gmail.com
}

\begin{abstract}
The author discusses the balance and mutual influence of the language of instruction and mathematics in the context of CLIL, Content and Language Integrated Learning. Different aspects of the relationship of language and Mathematics teaching and learning are discussed: the benefits of using a foreign language of instruction, as well as the advantages of using Mathematics as a tool to teach a foreign language. Based on research among pre-service teacher trainees, the author presents different approaches to CLIL-lesson planning, pointing out the focus of the teacher trainees on content and/or language and the development throughout the ongoing course of CLIL at the University, with respect to the different specializations of the teacher trainees.
\end{abstract}

Keywords: CLIL, mathematics, Teacher Training

\section{Introduction}

"In an integrated world, integrated learning is increasingly viewed as a modern form of educational delivery designed to even better equip the learner with knowledge and skills suitable for the global age." (Mehisto, 2008)

Content and Language Integrated Learning (CLIL) is a trend of growing importance in European education; it is a result of both European and American influence in fields of philosophy, psychology, education, and language learning.

CLIL refers to situations where subjects, or parts of subjects, are taught through a foreign language with dual-focussed aims, namely the learning of content, and the simultaneous learning of a foreign language. (Marsh et al, 1999).

In this paper, we shall discuss the mutual influence of Mathematics and foreign language in the context of a CLIL lesson and analyze the approach to a CLIL lesson planning of English-teacher trainees enrolled in a CLIL course.

\section{CLIL Methodology}

With its dual focus, CLIL draws on language teaching methods as well as the content subject didactics. According to Mehisto (2008), the core features of CLIL methodology are: its multiple focus, safe and enriching learning environment, authenticity, active learning and scaffolding. By scaffolding Mehisto understands building on students' existing knowledge, skills and experience, responding to different learning styles, fostering creative and critical thinking, and challenging the students to take a step forward.

Do Coyle designed a 4C Framework for CLIL. The four Cs stand for Content, Communication, Cognition and Culture. The Cognition factor corresponds to Mehisto's active learning and scaffolding. Coyle (2006) states that "all 4 Cs must be carefully considered in the planning and conceptualization stages of the teaching...content is the starting point, the effectiveness of what follows relies on the interconnectedness of the other Cs." Coyle uses Culture as a general term for a number of aspects ranging from the mother tongue of the learners, through a variety of socio-cultural variables to the learning environment and school curriculum. This factor is specific for every CLIL lesson, it refers to its unique context; however, the remaining three are universal for all CLIL 
activities. Let us discuss the mutual influence of these aspects, with focus on Mathematics as the content subject.

\section{English for mathematics}

According to the CLIL Compendium website, CLIL provides opportunities to study content through different perspectives, allows access to subject-specific target language terminology and prepares for future studies and/or working life. The last two aspects being self-explanatory, let us focus on the first one: how the content subject can actually benefit from a change of the language of instruction.

Hejný (Hejný et al, 2001) points out that the learners' superficial knowledge of the concepts and their properties is an issue frequently discussed in Mathematics. In this context, the word "formal" is used in the sense of "learnt by heart, without understanding the concept". CLIL can become a powerful tool of discovering such formalisms in knowledge and also a tool to eliminate them.

On the following examples, we shall illustrate how CLIL provides a different perspective in Mathematics, allowing for deeper insight and understanding. Marsh claims that "CLIL does not only promote linguistic competence. Because of the different thinking horizons which result from working in another language CLIL can also have an impact on conceptualization, literally how we think." (Marsh et al, 1999). The examples also illustrate the variety of benefits of CLIL for Mathematics in the context of Czech curriculum. Together with the Cs framework, the first example shows the content in different notation, the second one pictures the enriching experience of differences between the mother tongue (L1) and the language of instruction (L2) and the last example presents the cognitive changes that CLIL can bring.

In other words, learning Mathematics in a different language provides the learners with a different perspective on the content area; different vocabulary creates further associations; different methods necessary for instruction through a foreign language can trigger more active approach and deeper understanding.

Example 1 - The area of triangle. Formulas learnt isolated, as a segment of text learnt by heart, are often forgotten, misunderstood or altered by the students. CLIL forces the learners to go behind the formula, since with the change of the language of instruction, the labels and names of objects change, too. For example, the universally used Czech formula for the area of a triangle is this one: (a being the base of the triangle, and va standing for the height)

$$
S=\frac{a \cdot v_{a}}{2}
$$

However, in English, this formula looks different, although the concept is the same: one half of the base (b) multiplied by the height (h).

$$
A=\frac{1}{2} b \cdot h
$$

The foreign language of instruction does not allow students to rely on memorized letters of the theorem: it leads them to more concentration in the lessons and to understanding the underlying concepts.

Example 2 - The square. In Czech, there are different words for square as the geometric shape ("čtverec"), square as in the square power ("na druhou", "druhá mocnina") and a square as the part of the city ("náměstí"). There is no etymological, phonetic or visual bond between the individual Czech words, and subsequently, for many students the connection between the first two concepts is often formal, artificial. In this specific situation, using English makes the complexity of the notion very clear.

Example 3 - The shapes and their properties. The learners' non-proficiency in the language of instruction can also be used to advance their description skills and support their looking at the subject matter from different perspectives. In a CLIL classroom, groups of learners were given pictures of flat 
shapes and solids, and asked to describe them, first in their mother tongue (L1), and then in the language of instruction, in this particular experiment, English (L2). They were not pre-taught the L2 names or given dictionaries. Whilst the L1 descriptions typically featured only the name of the shape and provoked no discussion within the group, the L2 descriptions were intensely argued about in the group and the learners focused on the properties of the shapes, comparing them, counting individual parts, giving their relative position etc. Higher thinking skills (according to Blooms taxonomy) were activated in the foreign language: in L1, the Knowledge level was applied (define, label), whereas in L2 the learners spontaneously employed learning activities associated with Analysis, Synthesis and Evaluation levels (compare, contrast, examine, formulate, argue, select).

\section{Mathematics for English}

The CLIL compendium mentions the following points of the language dimension of CLIL: improvement of overall target language competence, development of oral communication skills, deeper awareness of both mother tongue and target language, and development of plurilingual interests.

These general notions have been specified by numerous researches. Dalton-Puffer (2006) claims that among the language competences favourably affected by CLIL are above all vocabulary, morphology, creativity, risk-taking, fluency, quantity and emotive/affective outcomes. On the side of the productive skills, Dalton-Puffer further argues that with regard to speaking, CLIL students often display greater fluency, quantity and creativity and show higher risk-taking inclination.

Learners of a foreign language often meet problems when faced with "real" communication. According to Hyde (2000), one of the reasons might be the artificiality of linguistic environment of a language class, where language is seen as the target, not a tool for real communication.

CLIL shifts the focus; the content factor provides the context and the subject; hence, a CLIL lesson naturally creates the need for new information: for example, in the abovementioned example 3, the situation triggered students asking for the vocabulary. In such situation, language is not formally learned but rather acquired though meaningful activities.

Furthermore, Mathematics facilitates CLIL by a wide range of its own symbolic notation and visual input: in a Mathematics lesson, the language of Mathematics (LM) creates a natural bridge between the mother tongue (L1) and the language of instruction (L2). This can help relieve the learners' stress of not knowing how to express the concepts or processes: they can rely on LM in the first stages and gradually expand their knowledge of L2.

\section{CLIL for cognition}

As far as the cognitive dimension of CLIL is concerned, the CLIL Compendium stresses its role in complementing individual learning strategies, diversification of methods and forms of classroom practice, increasing learner motivation, and improving learner attitudes to both the language and the content subject.

We have illustrated how the change of the language of instruction can trigger higher thinking skills. It has been proven that CLIL learners reach more often the limits of their expressive ability, which most frequently leads to intensified mental construction activity; they work more persistently on tasks, show higher tolerance of frustration, and have higher procedural competence (Vollmer et al, 2006).

Nixon (1998) claims that by teaching subject through a foreign language we not only simulate the conditions under which our pupils are likely to meet the language outside of school: we build their confidence and extend their knowledge, engage their curiosity and increase motivation. Novotná and Hoffmannová (2002) further prove that by employing diverse approaches CLIL provides a motivating environment that can address various learning-type students. Hence, CLIL can change attitudes of many students towards Mathematics in a positive way. (Novotná et al, 2002). In her research, 
Tejkalová (2006) has confirmed that CLIL Mathematics lessons have generally been perceived as motivating and challenging by the learners.

Having presented the benefits and interrelatedness of the individual aspects of CLIL, we shall analyze the teacher trainees approach to designing a CLIL lesson.

\section{The experiment: Teacher trainees' lesson plans}

The experiment was realized during one semester as a part of the teacher training programme at the Faculty of Education, Charles University in Prague as a part of an ongoing research targeted at the need of specific CLIL training for CLIL teachers. The aim of this experiment was to confirm that the specific-content teachers can plan a more balanced CLIL lesson and to explore how the teachertrainees lesson plans develop with gradually intensified exposure to CLIL.

Under the supervision of Department of Mathematics and Department of English, a CLIL course has been carried out. During this course, the students were expected to prepare and teach a CLIL lesson (specifically, a Mathematics through English-English through Mathematics lesson).

Groups and methodology. In the Czech Republic, secondary-school-teacher trainees specialize in two subjects; in the case of the experimental group one of the subjects was always English, whilst the second specialization differed. The group included 4 students of Mathematics, 2 of Humanities, one of Music and one student of German. All students prepared a CLIL lesson of Mathematics in English aimed for learners aged 13-14, with pre-intermediate level of English, and no previous CLIL experience.

First, the students attended lectures and seminars on CLIL specifics and analyzed video studies of various CLIL lessons. Second, they prepared their own teaching experiments and presented them (in a shortened version) in a peer-teaching session. A collective reflection on the lesson plans and the teacher trainees' performance in the session followed; each teacher trainee was then asked to elaborate on their materials, methods and strategies, incorporating the comments.

Next, they carried out the lessons at a secondary school. Each teacher trainee then wrote a selfreflection on the course of the lesson, focusing on the original targets, expectations, and the final results. They were also asked to comment on how they would change their preparation, were they to teach the lesson again. Simple questionnaires (in the mother tongue) were distributed among the participating secondary school learners, asking about the subjective difficulty of the lesson on the scale: very easy - easy - OK - challenging - difficult, the proportion of English and Mathematics in the lesson, the enjoyability of the lesson, and the difference of the methods employed in this lesson from the ones they are used to in their regular classes. The reflections and learners' questionnaires were then used in the CLIL course for a shared analysis a posteriori.

Results and evaluation. As expected, the initial lesson plans reflected the students' second specialization. Mathematics students (group M) opted for more complicated mathematical concepts corresponding to the actual level of the learners, and in terms of language they focused mainly on introducing and practicing the specific vocabulary. Despite the variety of Mathematics topics covered in the lessons, all of them were a revision for the learners, but allowed for different solving-strategies. The rest of the students (group H) aimed at easy Mathematics (primary school level), and incorporated ample non-mathematics-related language activities; they also managed to cover more language skills (Speaking, Writing, Listening, Reading) in their lessons. Whilst group M relied mainly on listening and writing, all members of group $\mathrm{H}$ included a reading assignment in their lessons. All students started their lesson in a lock-step approach, shifting later to individual, pair or group work, ending the lesson again in a whole-class activity. None of the original lesson plans analyzed the cognitive component of the lesson.

After the series of peer-teaching sessions, the students expanded on their lesson plans. Both groups scaffolded their presentations with more visual resources, 3 out of 4 members in M-group newly 
incorporated group work with role-assignment into their plans. There were generally more changes in the M-group lessons plans, reaching more balance between Mathematics and English and more variety in methods employed, admitting inspiration in the H-group peer teaching. In the H-group no further Mathematics concepts or problems were added, but the language part was elaborated on.

In the students' reflections, the most frequent issue was time-management. All of the students claimed to have designed a longer session than planned and had to manage the situations, usually by omitting some of the tasks or assigning them as homework. Three of the six students who opted for group-work faced problems creating the groups and admitted they had underestimated the necessity of clear and firm instructions. All of the students managed to fulfil at least $60 \%$ of their original aims. Seven of the eight students admitted that part of the tasks had been misunderstood or unclear for the learners.

Suggestions for their further CLIL lesson plans included more balance between the content and the language, paying more attention to non-mathematics vocabulary, the need of finer adjusting of the level of English for the learners, and the need for a more flexible lesson plan, allowing for customizable time-management.

The learners' questionnaires revealed the differences between the M-group and H-group lessons perceived by the students. The M-group teaching experiments were generally evaluated as "OK" or "challenging"; the average ratio of Mathematics to English was $65 \%$ Mathematics to $35 \%$ English, and the methods were perceived as "new, different, good". All of the H-group lessons were rated "very easy" or "easy", with the average percentage of Mathematics $12 \%$. The methods were mostly described as "fun" and "good". In both groups, the learners rated the experiment as enjoyable.

The experiment confirmed that Mathematics teacher trainees managed to create more balanced lessons at a level adequate for the learners. Their lesson plans and reflections also showed major development after each of the sessions. The non-Mathematics teacher trainees did not seek cooperation of their colleagues to adjust the level of Mathematics, and their lessons were perceived rather as an easy and enjoyable English lesson. Although both groups ( $\mathrm{M}$ and $\mathrm{H})$ employed the same variety of methods in their teaching experiments, in M group they were evaluated as innovative by the learners, which is probably due to the learners' perceiving the lesson more as a Mathematics one. On the other hand, in the lessons viewed by the learners as an English lesson, the methods were not perceived as exceptional.

\section{Conclusions}

We have analyzed the mutual influences and benefits of Mathematics and language in Content and Language Integrated Learning.

In teacher training, the Czech Republic can benefit from the dual qualification of the teachers, which allows them to exploit both language and content subject methodologies. The experiment further showed that hands-on experience with CLIL is challenging for the teacher trainees and facilitates deeper analysis of their general teaching approach.

One of the CLIL slogans is "Learn as you use, use as you learn." Apparently, it is not only valid for language acquisition in CLIL, but also for teacher training.

\section{References}

CLIL Compendium: Using Languages to Learn and Learning to Use Languages. http://www.clilcompendium.com (accessed April 2006)

Coyle, D. (2006). Monograph 6 Developing CLIL: Towards a Theory of Practice. Barcelona, Spain: APAC (Associació de Professors d'Anglès de Catalunya).

Dalton-Puffer, C. (2006). Outcomes and processes in Content and Language Integrated Learning (CLIL): current research from Europe. In Werner Delanoy and Laurenz Volkmann (eds.), Future Perspectives for English Language Teaching. Heidelberg, Germany: Carl Winter.

Hejný, M., Kuřina, F. (2001). Dítě, škola, matematika. Praha, ČR: Portál. 
28 European Journal of Science and Mathematics Education Vol. N, No. N, 201N

Hyde, J. (2000) "Teachers as learners: beyond language learning." http://eltj.oxfordjournals.org/cgi/reprint_1/54/3/265.pdf (accessed April 2006)

Marsh, D., and Langé, G. (1999) Implementing Content and Language Integrated Learning. Jyväskylä, Finland: Continuing Education Centre, University of Jyväskylä.

Mehisto P., Frigols M. J., Marsh D. (2008). Uncovering Clil: Content And Language Integrated Learning And Multilingual Education. Oxford, United Kingdom: Macmillan Education.

Nixon, J. (1998) “The Pains and Pleasures of Bilingual Education." www.euroclic.net/inhoud/bulletins/pdf/e11.pdf (accessed October 2008)

Tejkalová, L. (2006) CLIL: Content and Language Integrated Learning. Diploma thesis.

Vollmer, H. J., Heine, L., Troschke, R., Coetzee, D. and Küttel, V. (2006). Subject-specific competence and language use of CLIL learners: The case of geography in grade 10 of secondary schools in Germany. Presented at the ESSE8 Conference, London. 